\title{
Imaginar la nación:“5 a 0”, veinte años de monumentalización
}

\section{Imagine the nation: "5 to 0", twenty years of monumentalization}

\author{
Kevin Daniel Rozo Rondón' \\ Universidad Pedagógica Nacional, Colombia
}

\begin{abstract}
Resumen
Este artículo valora el potencial instituyente como imaginario nacional de la victoria 5 a 0 de la selección colombiana de fútbol sobre la argentina por las eliminatorias al mundial de Estados Unidos 1994, tras veinte años de monumentalización.
\end{abstract}

Palabras clave: Fútbol, identidad nacional, Colombia, Argentina.

\begin{abstract}
This article values the instituting potential, as national imaginary, of the victory 5-0 of Colombian national football team over Argentina in the World Cup qualifier to USA 1994, after twenty years of monumentalization.
\end{abstract}

Keywords: Football, national identity, Colombia, Argentina.

Recibido: 20 de noviembre de 2014 Aceptado: 20 de diciembre de 2014

\section{Introducción}

Según Pablo Alabarces, hasta hace muy poco las Ciencias Sociales se han detenido a estudiar el fútbol como hecho social, esto se debió, sobre todo (advierte el sociólogo argentino), al clásico calificativo del opio de los pueblos que se había desplazado como referente de la religión hacia el fútbol, decretando por mucho tiempo que constituía una herramienta de alienación de la sociedad. El fútbol es mucho más que eso (Alabarces, 2012). Este artículo valora la relación futbol-identidad nacional en nuestro país, tomando como referente algunos hitos que han "engrandecido" a la nación a partir del papel de la selección de fútbol, cuyo pico fue la victoria 5 goles por 0 frente la poderosa Argentina en septiembre de 1993.
El artículo está dividido en siete partes. En la primera presento algunas consideraciones de la naturaleza imaginaria de la identidad nacional; posteriormente, expongo algunos aportes teóricos que han contribuido a dilucidar las relaciones entre el fútbol y la identidad nacional; en tercer lugar esbozo algunas incidencias que tiene la enseñanza de las Ciencias Sociales en la conformación de la identidad nacional y cómo estas han cambiado con el tiempo en nuestro país; en el cuarto apartado, resalto algunos antecedentes del " 5 a 0 ", en particular, el recordado " 4 a 4" contra Rusia en 1962 y el " 1 a 1" frente a Alemania en 1990; luego, rememoro la Colombia de 1993 y valoro el impacto que tuvo la goleada nacional a la Argentina para los contemporáneos; en el sexto apartado estimo los efectos que tuvo el decisivo partido

1 Estudiante de Licenciatura en Educación Básica con énfasis en Ciencias Sociales, Universidad Pedagógica Nacional-UPN. Monitor de investigación del grupo "Educación y cultura política", del Centro de Investigaciones de la UPN (CIUP). Miembro de la Red de Investigación sobre Imaginarios y Representaciones (RIIR). Contacto: kevin_danielrozo065@hotmail.com 
en la sociedad y fútbol argentino; en el séptimo apartado, desde la distancia temporal, hago un balance de la potencia instituyente del 5 a 0 como imaginario de la nación y apuesto algunas posibles explicaciones al respecto.

\section{Identidad nacional: una cuestión imaginaria}

La identidad nacional es un imaginario social (Gómez García, 1998).Según Ugas, “El imaginario es la codificación que elaboran las sociedades para nombrar una realidad; en esa medida el imaginario se constituye como elemento de cultura y matriz que ordena y expresa la memoria colectiva, mediada por valoraciones ideológicas, autorrepresentaciones e imágenes identitarias" (2007: 49). Sin embargo, Bolívar et al. advierten que

[...] aludiralanacionalizacióndelasociedadyla estandarización de los distintos procedimientos de regulación de la vida social, no implica que en la construcción de nación todos se conviertan en iguales, o intercambiables, sino más precisamente que se definen las pautas de relación en las que unos aparecen como "nosotros" y los demás como grupos "de otros". La nación no coincide con el nosotros más o menos homogéneo, sino que la construcción de la nación se juega en la delimitación del nosotros como en la producción de un vínculo y de una diferencia con aquellos que van a aparecer como "los otros" (Bolívar et al., 2001: 24).

En efecto, la identidad nacional es el lugar en que la ipseidad se recoge en la otredad para constituir una totalidad imaginaria, que, en tanto tal, solo tiene existencia y razón de ser, condicionada a la diferencia que se logre establecer (y delimitar) con unotro no nacional. La identidad se afirma en la otredad, por ello, la identidad nacional requiere elaborar un conjunto de imágenes, hechos-pasados-en-común y símbolos-en-común que sinteticen el nosotros nacional y sean lo suficientemente "autóctonos", cuando no "únicos", como para diferenciarse satisfactoriamente de esos otros no nacionales. El fútbol, por lo menos en nuestro país, no escapa a ese conjunto de imágenes, hitos y símbolos nacionales. Digámoslo de una vez: el fútbol es una actividad cultural que configura imaginarios de identidad nacional.

\section{Fútbol e imaginario nacional}

Para Pablo Alabarces el fútbol constituye "un lugar en torno del cual se construyen identidades e imaginarios, como una arena dramática casi sin equivalentes, como espacio ritual de masas por excelencia" (Alabarces, 2002: 11). En nuestros tiempos, esta actividad cultural cobra un valor decisivo y un tanto paradójico en la configuración de identidades globales y locales, pues por una parte, hoy el fútbol se globaliza a pasos agigantados y, por otra, cada vez más radicaliza su localismo. Lo último, según Alabarces, se puede explicar por el hecho, cada vez más evidente, de la crisis inminente de varias de las narrativas, valores e instituciones clásicas que orientaban los estados-nación y, por efecto, sus respectivos imaginarios de identidad. Este vacío lo empezará a ocupar el fútbol en varias sociedades (Alabarces, 2002). Entonces, ante la debilidad social del Estado y la falta de relatos inclusivos para el grueso de la población,

pasan a primer plano otras formas de nacionalidad, que existieron antes, pero que nunca como hoy cubren todos los vacíos de creencia. En el estallido de identidades [...] el fútbol opera como aglutinante: es fácil, universal y televisivo. No es la nación, sino su supervivencia pulsátil. O quizá, la forma en que la nación incluye hoy a quienes, de otro modo, abandona (Alabarces, 2002: 11).

Con todo, lo cierto es que hoy las identidades vinculadas al fútbol cobran más importancia que nunca, máxime cuando de identidad nacional se trata. La condición de "hincha" parece ser una figura obligada para el ejercicio de la ciudadanía nacional. Así, el buen ciudadano debe apoyar y sentir júbilo por los triunfos de sus compatriotas deportistas en el exterior, lugar donde, en 
nuestro caso, la selección colombiana de fútbol parece ser el mayor referente de esta relación identitaria, detentando un poder movilizador social y mediático superior a las demás.

\section{Enseñanza de las ciencias sociales e identidad nacional}

En el proyecto de construcción de nación, la escuela, como institución estratégica para la reproducción de los valores dominantes, adquiere vital importancia, pues sería allí (en alianza con la familia tradicional y la iglesia católica) donde se configuraría la identidad nacional de nuestro país, por los menos hasta la primera mitad del siglo XX. El discurso era la viva expresión de los imaginarios de las élites, referentes a cómo debería ser "lo nacional". El ideario de unidad nacional, la comprensión del territorio nacional, el entendimiento de la ley, la imposición de la religión católica, el manejo de la lengua castellana - que niega a las demás lenguas que yacen en el territorio- y la iconografía patriótica son los elementos representativos del mensaje que se quería transmitir en la escuela en la formación de los nuevos ciudadanos. Ello se puede evidenciar en el estudio de los manuales escolares de Ciencias Sociales, desarrollado por el Grupo de Investigación Educación y Cultura Política:

La intención de los manuales era promover el ideario de la unidad nacional a partir de referentes como el territorio, entendido como el espacio en el que cobra vida la nación; la ley, como fuente de orden y gobernabilidad de los sistemas republicanos, las religión católica, como modeladora del alma nacional; la lengua castellana, como vaso comunicante de la población y la iconografía patriótica, como fuente de los arquetipos que hay que imitar (...) respecto a los imaginarios del ciudadano, se tomó como referente a la aristocracia europea y se pensó en un ciudadano blanco y culto. Para la realización de este modelo era necesario limpiar lo que había en nosotros de indígena y negro, papel en el que la escuela y la iglesia ocupaban un lugar protagónico (Herrera, 2007).
En este proyecto la enseñanza de una historia nacional desempeñaría también un papel imperativo. Desde entonces, en los manuales escolares y enciclopedias de historia de Colombia se inmortalizarían hitos decisivos del pasado-encomún de la nación, tales como "la batalla de Boyacá", "la guerra contra el Perú", "el 9 de Abril" o "la pérdida de Panamá".

No obstante, más recientemente, el imaginario nacional ha sufrido transformaciones, máxime con la constitución de 1991 con la que Colombia es declarado un país pluriétnico y multicultural, con libertad de culto, y un entramado de referentes que dan lugar a nuevas significaciones imaginarias sobre la nación y lo nacional, donde el deporte en general, y el fútbol en particular, ocuparán un papel decisivo. Con todo, lo que resulta sugerente para nuestro análisis es ver la manera en que la victoria 5 a 0 de la selección colombiana de fútbol frente a la argentina, por las eliminatorias al mundial de Estados Unidos 1994, se ha ido ganando un lugar, aún modesto, en las enciclopedias de historia de Colombia que, junto a los manuales escolares, constituyen los textos recontextualizadores de la cultura por excelencia, compartiendo plaza con "los grandes hechos nacionales". Veamos un ejemplo,

El histórico triunfo 5 a 0 sobre Argentina: el 15 de agosto de 1993 se enfrentaron Colombia y Argentina en Barranquilla, donde ganamos 2-1 y quedamos de primeros del grupo con 5 puntos, uno más que Argentina. Se trataba de la eliminatoria para el mundial de fútbol de 1994, en Estados Unidos. Vino un segundo encuentro de estos dos equipos, el 5 de septiembre de 1993 en el Estadio Monumental, de Buenos Aires. A los 41 minutos del primer tiempo, Fredy Rincón hizo el primer gol. El segundo tiempo se sucedieron anotaciones de Asprilla a los 5 minutos; Rincón a los 28; Asprilla a los 30 y "El Tren" Valencia a los 39. Los argentinos resignados, nos aplaudieron, entre ellos Maradona (Colombia Viva, 2000:283).

Este fragmento de una enciclopedia de historia nacional es un ilustrativo ejemplo del poder instituyente que socialmente ha tenido el 5 a 0 
como hito nacional. Hito nacional, no solo por la grandeza del hecho y la preocupación porque eso grande permanezca en el tiempo, sino también por la alta carga de "colombianidad" que este hecho porta intrínsecamente, porque aquí no fueron los once del campo de juego, vestidos de pantalones cortos y medias largas quienes ganaron; no, aquí fue todo un país quien ganó: ganamos. Dado dicho triunfo, no fue al equipo de jugadores colombianos en el Monumental a quienes resignados, los argentinos aplaudieron incluyendo a Maradona; no, fue a todos los colombianos a quienes nos aplaudieron. Los once de la cancha vestidos del tricolor, por 90 minutos, representan la nación y lo nacional. Allí la frontera entre los jugadores como otros y los espectadores como nosotros se difumina, jugadores y espectadores somos nosotros, jugadores y espectadores somos Colombia.

\section{Antecedentes: crónica de dos empates con sabor a victoria El "4 a 4"}

Chile 1962 sería el debut de la selección colombiana de fútbol en un campeonato mundial. Para entonces, dicha participación constituía un triunfo por sí misma para el deporte colombiano. La opinión pública de la época calificaba la clasificación como un paso histórico para el balompié nacional. Pues bien, tras haber caído 2 a 1 en el primer partido contra Uruguay, los ánimos seguían en alto y con gran expectativa frente al partido que se avecinaba contra la Unión Soviética. El 3 de junio de 1962 Colombia empataría a cuatro goles con el seleccionado ruso, hecho que por mucho tiempo constituiría la mayor hazaña del seleccionado tricolor, que para la época era azul y blanco y despertaba emociones desde la radio, porque ni transmisión televisiva masiva había por entonces.

Sí, un empate: la igualdad constituyó la "consagración de la selección Colombia dentro del fútbol mundial". Así lo expresaría la prensa nacional justo un día después de la mencionada hazaña. Veamos:
Colombia logró esta tarde su consagración dentro del futbol mundial, al empatar a 4 goles un partido con la Unión Soviética, que había comenzado perdiendo por tres a cero. Los colombianos, inspirados extraordinariamente, no se dejaron vencer por la desmoralización de lo que parecía una goleada segura; terminaron el primer tiempo con un marcador desfavorable de tres a uno; y en la etapa complementaria descontaron los otros tres de la ventaja rusa (EI Tiempo, lunes 4 de junio de 1962).

Un empate sentaba las bases para una historia apoteósica del fútbol nacional. Fútbol e identidad nacional empezaban a coquetear: "por gestas así la mitología es una religión de los pueblos con historia. Hoy es día de izar bandera nacional" (EI Tiempo, lunes 4 de junio de 1962). El tamaño de la celebración indicó júbilo nacional, la carencia de victorias en esta materia puso en un pedestal un modesto, pero sufrido" 4 a 4",

[...] por eso será eterno. Quince millones de colombianos, ni uno menos, estuvimos el domingo 3 de junio de 1962 con el oído pegado a la radio y el corazón puesto en Arica. En las veredas, poblaciones y ciudades de la patria estalló una reacción en cadena, con muy pocos antecedentes en la memoria nacional (Ibídem.).

El "4 a 4" empezó a tener un definitivo sabor a victoria, su impacto en la población nacional devino en gesta nacional, como si Colombia hubiera ganado una guerra, o como si se hubiera vuelto a caer Rojas Pinilla, el país se estremeció ayer de júbilo después de vivir, minuto a minuto, la hazaña del seleccionado nacional de fútbol al empatar en Arica a la Unión Soviética (Ibídem.).

Los mensajes políticos no se hicieron esperar, en palabras del ministro de Educación de la época:

el país sin excepción, ha querido exteriorizar su entusiasmo. Ha sido, en Colombia, una gran jornada de solidaridad nacional. $Y$ en Chile, con nuestros representantes deportivos, una ejemplar demostración para el mundo de los 
resultados de la perseverancia, del coraje, de la eficacia coordinada, de la ambición hacia altas metas. Un empate que, en el segundo tiempo del juego, fue el indudable dominio victorioso del seleccionado colombiano (Ibídem).

Esto tiene un valor decisivo, dado que desde aquel entonces se comienza a vislumbrar una suerte de instrumentalización política de las victorias futbolísticas del seleccionado nacional. Tras la hazaña deportiva de un compatriota en el exterior, las autoridades políticas no pueden guardar silencio, deben manifestar públicamente su reconocimiento. El discurso de felicitación a David por derrotar a Goliat (o empatar, que al final parece ser lo mismo dependiendo de la grandeza del rival), resaltando los valores de la perseverancia, el esfuerzo, la disciplina, y la superación de las dificultades, en el contexto de un país rezagado que quiere superarse, constituiría de ahí en adelante un recurso político indispensable para hacer sentir más la nación y lo nacional. El fútbol era utilizado como metáfora de la nación.

Posterior al vanagloriado " 4 a 4" el seleccionado nacional cae por cinco goles a cero contra Yugoslavia, partido con el cual quedaría totalmente eliminado de la cita mundial con un solo punto "para la historia" y como último del grupo por debajo de la Unión soviética, Yugoslavia y Uruguay. Sí, esta fue la gran hazaña, la ópera prima de los nuevos héroes de la nación. $Y$, en efecto, como héroes fue el recibimiento de sus compatriotas. Escuchemos las coloridas palabras del archivo:

[...] bienvenida para héroes, puede llamarse el espectáculo ofrecido por la ciudadanía bogotana durante las dos horas 20 minutos que duró el recorrido del aeropuerto El Dorado al Hotel San Francisco. El Himno Nacional, la aclamación permanente y el agitar de pañuelos en medio de una masa humana que rodeaba el bus, fueron el premio que Bogotá ofreció a sus futbolistas que por primera vez llegaron a unos octavos de final de un campeonato mundial (EI Tiempo, domingo 10 de junio 1962).
Este punto resulta muy importante para contrastarlo con algunos problemas contemporáneos. La prensa de la época no registró mayores altercados de orden público, riñas ni mucho menos muertos en las celebraciones de los colombianos por el citado empate con sabor a victoria contra el seleccionado ruso. Tampoco se narran batallas urbanas de maizena, espuma, ni cosa que se le parezca, menos aún de grandes conflictos provocados por el exceso de alcohol. Pañuelos de colores agitados en el aire y banderas tricolor parecían ser el resumen de una celebración sin desórdenes. Esto es clave pues, como veremos, la celebración del "1 a 1"contra Alemania, 28 años después, ya tendría algunos de estos ingredientes, y el " 5 a 0 " parece haber inaugurado el matrimonio triunfo de la selección nacional de fútbol-celebración violenta, con su trágica cuenta de 82 muertos y 725 heridos. Esto da lugar, por supuesto, a una futura investigación dedicada estrictamente al particular; sin embargo, aquí podemos valorar el carácter histórico del hoy tan citado "no sabemos celebrar". La violencia y la "celebración trágica" de ningún modo son naturales e inherentes al pueblo colombiano, son un producto sociocultural históricamente determinado, que hoy más que nunca resulta imperativo comprender.

Con todo, hoy podemos argüir que el" 4 a 4"logró instalarse en la memoria deportiva de los colombianos por mucho tiempo, fundamentalmente gracias a cinco factores: en primer lugar, la nula historia de victorias futbolísticas (y deportivas en general) con que contaba el país hasta la época; en segundo lugar, el carácter deprimido de la sociedad colombiana que ya era víctima de la violencia; entonces, cualquier "noticia positiva" constituía un respiro para la población; en tercer lugar, la condición de debutante de la selección en las copas del mundo; cuarto, la grandeza atribuida al rival en esos tiempos y, sobre todo, a su portero, Lev Yashin, la legendaria "araña negra"(janotarle cuatro goles no era tarea fácil!); $y$, por último, el valor agregado que otorga anotar un gol olímpico en un certamen de tal tamaño, que hasta ahora ha sido el único y ha hecho de Marcos Coll un nombre imborrable de la historia de las copas del mundo. 


\section{El“1 a 1"}

El 19 de junio de 1990, sobre la alfombra del mítico Giuseppe Meazza, la selección cafetera enfrentaría el mayor desafío futbolístico de su historia: retar a la poderosa Alemania de Matthaeus, Littbarski y compañía (que finalmente se coronaría campeona del certamen), nada más y nada menos que por lograr por primera vez una clasificación a una segunda fase del mundial de fútbol, ahora en Italia. Tras haber derrotado al seleccionado de Emiratos Árabes por un contundente 2 a 0 y haber caído por un gol frente a Yugoslavia en los dos primeros partidos de la fase de grupos, la tricolor soñaba con dar el gran paso.

Pues bien, en un apretado partido, cuyos protagonistas habían sido la sólida defensa colombiana y la puerta segura de René Higuita, y a tan solo un par de minutos de la esperada clasificación que con el sufrido 0 a 0 alcanzaba, un gol inesperado de Pierre Littbarski oscureció el sueño mundialista para los colombianos. No obstante, en un acto como de película, solo tres minutos después, en el ocaso del tiempo extra del segundo tiempo, a Leonel Álvarez se le ocurre juntarse con el Pibe Valderrama, quien sacará toda su genialidad y asistiera de manera impecable a Freddy Rincón para que sellara con gol un nuevo empate con sabor a victoria para el pueblo colombiano.

De nuevo la celebración generalizada y el júbilo nacional motivados por un empate se hicieron presentes, "era como si Colombia hubiera alcanzado la cota más alta de alegría, el empate, no una victoria, colmó el ánimo de un pueblo golpeado por la violencia y la desesperación" (El Espectador, 24 junio 1990).Una vez más el país seguía deprimido por la violencia y una noticia de este tipo daba un nuevo respiro a "los nacionales". Y es que desde hace 28 años no pasaba algo de esta dimensión, por eso había que celebrar, incluso, "se improvisaron pistas de baile en la mayoría de los barrios de la ciudad, en las principales vías y en parques públicos" (EI Espectador, 20 junio 1990). Colombia otra vez estaba de fiesta. Empero, como ya se mencionó en el apartado anterior, aquí empiezan a emerger algunos elementos de la celebración violenta y descontrolada: "los exaltados se pasaron de revoluciones y en oportunidades abusaron y quisieron hasta voltear automóviles. Ello, unido a la 'rociadita' de maizena provocó algunas peleas callejeras que hicieron necesaria la intervención de la policía" (Ibídem) Sin embargo, según el balance presentado por la prensa de la época, el caos no pasó a mayores. Entonces, harían falta algo así como tres años para presenciar esa paradoja de la celebración como tragedia.

Igualmente, el discurso político vinculado al patriotismo y la esperanza en medio de las dificultades no se hizo esperar, "¿para Colombia qué significa este empate, que realmente es un triunfo, señor presidente? Para todos los colombianos creo que significa un triunfo del país que inspira un gran sentido patriótico y el agradecimiento de todos" (Ibídem). Del mismo modo, al regreso de la selección a Colombia tras haber sido eliminada en la tan esperada segunda ronda contra Camerún, los jugadores y el cuerpo técnico fueron recibidos heroicamente:

[...] tras un agotadorviajellegó ayer la selección colombiana. El equipo llegó inicialmente a Cali, donde se quedaron algunos y, posteriormente, hacia las once de la mañana aterrizó en EI Dorado donde millares de personas se quedaron esperando para tratar de festejar el regreso del equipo (El Espectador, 28 junio 1990).

No importaba mucho si los héroes deportivos de la nación empataban o perdían, había que recibirlos "como lo que eran", héroes. Con todo, la época de tratar los empates como victorias estaba por terminar:

[...] duró el futbol colombiano viviendo durante 28 años del empate 4-4 ante la Unión Soviética. Se hizo después de tantos fracasos un plan serio, que podía llegar más lejos. Pero no fue así. Después del empate frente a Alemania Federal, se armó la fiesta más grande, se creyó coger el cielo con las manos. La dimensión tan pequeña 
de nuestras aspiraciones llevó a eso: apenas un empate ante los alemanes, que significaba, un tercer lugar, es decir, el penúltimo lugar entrando por la puerta de los invitados y no por la de los ganadores (El Espectador, 25 junio 1990).

Una historia nacional no se puede fundar sobre una derrota o un empate; una historia nacional se vale de hitos triunfales, de grandes gestas que merecen ser recordadas por "los nacionales" y que "engrandecen" la nación para siempre. El matrimonio imaginario entre la selección colombiana de fútbol y la identidad nacional necesitaba aun una proeza, una verdadera victoria para contársela a sus compatriotas por el resto de la historia.

\section{Conciencia interna del tiempo: El " 5 a 0 " hace veinte años}

Hay hechos sociales que resultan significativos para una sociedad de forma tal que ella misma, en su condición contemporánea, puede decir que dichos hechos tienen un carácter histórico, hechos que marcan una nueva época."Colombia destrozó la historia": así se titulaba una columna del diario El Tiempo del 6 septiembre de 1993, solo un día después de la hazaña tricolor:

[...] esta es una historia de amor en la que un eterno aspirante a la graduación no sólo pasó el examen, sino que alcanzó el título con los máximos honores. Así se va Colombia para el Campeonato Mundial de Estados Unidos-94. Un finalfelizqueabre un senderohistóricoen elfútbol colombiano por esta fenomenal goleada de 5-0 sobre Argentina para no dejar, definitivamente, ninguna duda por esta evolución de la que tanto se pondera en el mundo prepotencia (EI Tiempo, 6 de septiembre de 1993).

En efecto, para la colombianidad el "5 a 0" demostró que "La historia sí se hace y se escribe todos los días", tal como rezaba otro encabezado de la prensa de aquel momento:

Definitivamente, Maradona no las tiene todas consigo. Minutos antes de comenzar el partido, acá en Buenos Aires, el otrora rey del fútbol vociferaba desde su palco de honor en el estadio deNúñezqueeraimposiblequeColombiaganara el partido porque Argentina representaba la historia misma del fútbol y que la historia no se podía cambiar. Abajo, en el camerino, Maturana recibió con discreta sapiencia el puntillazo de Maradona. El reposado técnico colombiano, mirando al cielo azul que cobijaba al escenario, expresó: "La historia se hace todos los días". Dos horas más tarde el encuentro había concluido. El 5-0 simbolizaba el triunfo de la grandeza sobre la prepotencia (lbídem).

La opinión pública colombiana tenía entonces, digamos, una suerte de conciencia interna del tiempo que le vaticinaba que la historia deportiva nacional había sufrido un quiebre y se advenía una nueva época. "Homenaje a Selección Colombia": este fue el titular del diario El Tiempo el 7 de septiembre de 1993. Aquí se empieza a visibilizar la potencia instituyente del 5 a 0 como imaginario de la nación:

Por intermedio del Alcalde Mayor y del Concejo, la ciudad de Bogotá rindió homenaje a la Selección Colombia. Mediante decreto 510 del 6 de septiembre, el Alcalde Jaime Castro, declaró ciudadanos ilustres a los integrantes de la Selección Nacional de Fútboly su cuerpo técnico y consagró Día Cívico el de ayer [...] ]el Concejo expidió un comunicado donde se expresa que la corporación y su mesa expresan a la selección Colombiayasus entrenadores un efusivo saludo de bienvenida y se unen a las manifestaciones de felicitación y júbilo del pueblo colombiano a un grupo de deportistas que ha demostrado lo que se puede realizar cuando se tiene disciplina y se superan numerosos obstáculos personales yeconómicos.

El "5 a 0" empezó a ser más que un partido de fútbol para erigirse paulatinamente como un símbolo que sintetiza el espíritu de la nación, el modo en que la "tenacidad", la "perseverancia" y el "trabajo en equipo" pueden conseguir grandes logros en medio de las adversidades en ese país de tres colores donde el rojo parecía ser el más 
abundante. Echemos un vistazo a otra columna de la coyuntura nacional:

Lo que Maturana y sus muchachos nos han enseñado hoy es que todo lo que se hace con fe, con organización, unidad de propósitos y con una devoción a toda prueba, conduce inevitablemente al camino luminoso de las metas cumplidas, que es cuando se convierten en goles las sinfonías del alma (EI Tiempo, 6 de septiembre 6 de 1993).

La sociedad colombiana sintió entonces que algo había pasado en la historia y, era tan grande, que abría de recordarse para siempre. "Por eso, hay que empezar con la alineación para que se instale en la memoria para siempre: Córdoba; Herrera, Perea, Mendoza y Pérez; Rincón, Gómez, Álvarez y Valderrama; Asprilla y Valencia." (Ibídem; el subrayado es nuestro).Todo hito nacional tiene sus héroes, el " 5 a 0 " tiene los suyos. El " 5 a 0 " tiene un sentido para la nación que trasciende los cien metros del césped y el ruedo de una pelota: "Colombia 5-0 tiene otro significado, muy por encima de los linderos deportivos. Es el triunfo de un pueblo que está convirtiendo sus sueños imposibles en realidades tangibles de amor y esperanza" (Ibídem).

Con todo, lo cierto es que el 5 a 0 , como sea que se interprete, como sea que se instrumentalice, para la Colombia de 1993 fue sumamente significativo. Podemos sentir la emoción en cada palabra de los diarios citados, y qué decir de la narración del partido cuando a William Vinasco se le ocurre decir que todas las autoridades nacionales y departamentales deberían declarar el día cívico por tan apoteósica hazaña. ¡Y lo hicieron!

No fue un empate, no fue ante un chico, no fue en casa, no fue un partido cualquiera; fue la mayor victoria de la selección colombiana de fútbol hasta la época, ante un grande y en su casa. Fue la mayor celebración de todos los tiempos, fue la más violenta de todas, fue la mayor tragedia humana producto de la alegría y el júbilo nacional: 82 muertos y 725 heridos. Fue el triunfo de la maizena, el alcohol, los accidentes de tránsito, las riñas y la muerte, fue el triunfo del matrimonio triunfo de la selección nacional de fútbol-celebración violenta, que hoy aun es menester estudiar minuciosamente. Con todo, resultaba difícil olvidar ese 5 de septiembre de 1993.El 5 a 0 contaba con una potencia instituyente; como imaginario de la nación.

\section{“La peor derrota de la historia"}

\begin{abstract}
“¡Vergüenza! Desde Suecia no hacíamos un papelón así. ¿Basile debe renunciar? Ahora nos queda entrar por la ventana. ¿Maradona es culpable o inocente?" (El Gráfico, 7 de septiembre de 1993).Así iniciaba la recordada "tapa negra" de El Gráfico en Argentina tras la caída por cinco tantos frente al seleccionado colombiano.
\end{abstract}

Futbolísticamente hablando el 5 a 0 no fue un partido cualquiera, la tricolor venció de manera contundente a un gigante del fútbol mundial en su casa, le complicó su clasificación al mundial, y constituyó hasta ahora la mayor derrota de todos los tiempos de la albiceleste. Como lo diría el informativo argentino Cancha Llena veinte años después en su columna titulada "Un aniversario que duele: el 0 a 5 ante Colombia cumple 20 años": "sencillamente, el equipo conducido por Alfio Basile sufrió la peor derrota de la historia" (5 de septiembre de 2013). El golpe que recibió la Argentina, producto de la monumental derrota frente a Colombia, fue de proporciones similares al júbilo de los cafeteros por la victoria. Recordemos un pasaje de la polémica tapa negra de El Gráfico tan solo un par de días después del decisivo partido:

[...] una Selección Argentina puede ganar, empatary perder. Puede jugar bien o no. Lo que tiene absolutamente prohibido, lo que altera, lo que denigra, es el papelón, la vergüenza interminable de esta goleada lapidaria, letal, que acaba de propinarnos Colombia (El Gráfico, 7 de septiembre de 1993).

El desastre y la desconfianza fue tal, que la Argentina tuvo que llamar a gritos a su más legendario héroe. Diego Armando Maradona 
había anunciado su retiro de la selección argentina después del Mundial de Italia 1990 y su prueba de dopaje positiva en 1991 aumentó su alejamiento de las canchas.

El ¿ex? jugador fue como hincha a ver el partido, pero se fue preocupado y ovacionado por el público, que coreó el famoso "Maradoooooooo Maradooo0oo" y provocó un clic en el 10, que en menos de un mes se puso en forma, fichó para Newell's, formó parte del plantel que le ganó en noviembre el repechaje a Australia y fue al Mundial de Estados Unidos (Cancha Llena, 5 de Septiembre de 2013).

El partido del 5 de septiembre de 1993 hoy es recordado por los colombianos como un relato triunfal del deporte nacional y por los argentinos como aquella gran derrota en casa sin precedentes. Empero, el 5 a 0 no solo es recordado por colombianos y argentinos, también los es por varios simpatizantes y conocedores del fútbol en nuestra región. Al respecto, columnas como "A 20 años del 5 a 0 de Colombia a Argentina en el Monumental", publicada por el informativo Perú 21, se afirma que "El 5 de septiembre de 1993 el equipo conducido por Alfio Basile sufrió la peor derrota de la historia" (5 de septiembre de 2013). Aquella se suma a un conjunto de noticias y documentales especializados presentados por cadenas deportivas latinoamericanas que contribuyen a la creciente monumentalización del decisivo triunfo: el 5 a 0 no fue un partido cualquiera.

\section{Imaginar la nación veinte años después}

Luego de veinte años de aquel 5 de septiembre de 1993, cuando la selección colombiana de fútbol se impuso 5 a 0 al seleccionado argentino por las eliminatorias de clasificación al mundial de Estados Unidos1994, hoy se sigue recordando este decisivo triunfo del combinado tricolor. Se añora ese juego impecable, el "toque toque", la solidez táctica del"4-4-2"y, ante todo, el gol.

Ahora bien, los porqué relativos a la potencia instituyente del " 5 a 0 " como imaginario de la nación aún no resultan muy claros; sin embargo, hay algunos elementos que en conjunto pueden brindarnos algunas pistas. Primero, Colombia es un país futbolero, de hecho, hoy después de veinte años por fin tenemos una detallada encuesta nacional sobre la importancia del futbol en nuestro país, esta encontró que para el $94 \%$ de la población nacional, sin distinción alguna, es importante este deporte en sus vidas (CNC, 2014:19). Segundo, pese a la gran pasión por este deporte, hasta la época Colombia padecía de una escasa, cuando no nula, historia de triunfos. Tercero, la tricolor venció de manera contundente a un gigante del fútbol mundial en su casa, le complicó su clasificación al mundial, y constituyó hasta ahora la mayor derrota de todos los tiempos de Argentina y a su vez fue la primera gran victoria del seleccionado colombiano. Cuarto lugar, como se ha visto, la crónica deportiva tiende a mitificar las hazañas deportivas a partir de narrativas apoteósicas, con las cuales se contribuye a la monumentalización de las proezas deportivas en el mundo social. Ya lo advertía Mario Vargas Llosa,

para comprobar prácticamente cómo la buena literatura transforma la experiencia real en mito ¡lean las crónicas de fútbol! Estos periodistas deportivos, cuando son talentosos, jamás describen un partido o radiografían el desempeño de un jugador; lo mitifican, es decir, lo sacan de su efímera, pasajera realidad concreta y los instalan en la realidad permanente, intemporal e incorpórea de la ficción (citado en Galo Mora, 2003: 6).

Por último, un país deprimido en una interminable historia de violencia, con pocas anécdotas triunfales que contarle a sus compatriotas, encontró en la imponente victoria sobre Argentina una narrativa en la que los colombianos se pudiesen sentir universales: el "5 a 0"constituyó, entonces, un triunfo de triunfos, y con la potencia mediática a su favor se prepararía para instalarse paulatinamente en el concierto de los imaginarios que constituyen la colombianidad. 
Son veinte años de memoria social, de monumentalización, de construcción de imaginarios de identidad nacional. La monumentalización, según Nietzsche, es la exigencia de que lo grande debe ser eterno: "EI hombre extrae de ella la idea de que lo grande alguna vez existió, que en cualquier caso, fue posible y por lo tanto, también quizá sea posible de nuevo" (Nietzsche, s.f.:55).

La monumentalización del " 5 a 0 " se ha materializado de diferentes maneras en los últimos veinte años. La hazaña tricolor de septiembre de 1993 se ha convertido en un acontecimiento de la historia nacional inmortalizado en una diversa publicación de libros, revistas, documentales y enciclopedias de historia de Colombia. Incluso, recientemente se produjo una serie de televisión que pretendió sintetizar las hazañas de "la selección", donde el " 5 a 0 " se presenta como el pico de la gloria. Hoy el "5 a 0" hace parte de la memoria social de los colombianos vinculada al imaginario nacional: niños, jóvenes, adultos y viejos recuerdan con emoción los pases de Valderrama y los goles de Asprilla y compañía como si hubiera sido apenas ayer.

"20 años de un 5 a 0 que es inolvidable": así se titula una columna del diario El Tiempo del 5 de septiembre de 2013 que se celebra los 20 años de la decisiva victoria tricolor en el estadio Monumental:

El 5 de septiembre de 1993 es una de las fechas patrias del fútbol colombiano. Hoy, 20 años después de que la Selección Colombia lograra la hazaña de derrotar 5-0 a la siempre poderosa Selección de Argentina y en el estadio Monumental de River Plate de Buenos Aires, en la mismísima cancha en la que levantaron por primera vez el trofeo como campeona mundial, 11 futbolistas colombianos, varios de ellos con nombres como sacados de una novela de Gabriel García Márquez; golearon, clasificaron al Mundial de Estados Unidos-1994 y terminaron ovacionados por 60.000 estupefactos hinchas argentinos, entre ellos
Diego Armando Maradona, que no tuvieron alternativa distinta a la de ponerse de pie y aplaudir el soberbio triunfo (...) Y fueron los mejores del mundo, sí, lo fueron por lo menos esa noche del 5 de septiembre de 1993 cuando Colombia goleó 5-0 a Argentina, Maradona la aplaudió de pie y 20 años después aún pone a gritar los goles de Rincón, 'Tino' y el 'Tren' como si hubieran sido anotados apenas ayer... (el subrayado es nuestro).

El 5 a 0 hoy constituye un hito nacional que reafirma el valor que tiene la selección nacional de fútbol para los colombianos. Según la reciente encuesta nacional sobre la importancia del fútbol en nuestro país realizada por el Centro Nacional de Consultoría (CNC), sobre una muestra de 2.745 colombianos de diferentes estratos poblacionales, se halló que: "el $96 \%$ de los ciudadanos encuestados opina que la Selección Colombia es un símbolo de integración. El sentimiento de orgullo por el seleccionado nacional es generalizado en todas las regiones del país y no se altera por sexo ni por rango de edad" (CNC, 2014:40).

Hoy cabe decir que, por lo menos en términos imaginarios y en determinadas condiciones, la selección colombiana de fútbol puede sintetizar el espíritu de la nación:

[...] la afición por la Selección Colombia aglutina al país. Losjugadores que la conforman representan nuestra diversidad. El $86 \%$ de los encuestados se reconoce seguidor dela Selección y el 95 \% considera que los jugadores inspiran a los jóvenes a superarse. La población general expresa que se siente orgullosa de la Selección Colombia, sin distingos de estrato social; tanto hombres como mujeres expresan su orgullo con porcentajes mayoritariamente sobre el 90\% (CNC, 2014: 41).

Esto tiene sentido dado que "los colombianos reconocen que los jugadores de la Selección son ejemplo para el país por su entrega y profesionalismo. Representan el ideal de la identidad nacional. Hoy en día, la Selección 
nos permite fortalecer el orgullo de ser colombianos"(CNC, 2014: 41). Con todo, hoy "el fútbol puede ser la gran metáfora del país (...) El cuidado y el respeto a los ídolos del fútbol son un ejemplo para el cuidado y respeto del colombiano y de lo colombiano" (CNC, 2014: 44).

Pues bien, aceptando la posibilidad de pensar la figura de la selección colombiana de fútbol como una -de varias posibles- síntesis de la colombianidad, creemos que el " 5 a 0 " constituye, en tanto "gran gesta", el hito fundacional de este nuevo imaginario de la nación. El 5 a 0 durante 90 minutos engrandeció la nación, para unos por encima de América Latina, para otros más por encima del mundo entero. El 5 a 0 marcó ese gran momento en que la selección nacional de fútbol, y la colombianidad, se convertirían de ahí en adelante en una sola.

Con todo, lo cierto es que la victoria 5 a 0 de Colombia sobre Argentina por las eliminatorias del mundial de Estados Unidos 1994, con el tiempo, ha ganado un significativo poder instituyente, posicionándose así como un hito nacional dentro del concierto de los imaginarios que dan sentido a la nación, diversificando sus maneras de pensar, sentir y decir lo nacional.

\section{Referencias}

Alabarces, P. (2012). “Entre la banalidad y la crítica: perspectivas de las Ciencias Sociales sobre el deporte en América Latina". En, Quitián, D., Estudios socioculturales del deporte: Desarrollos, tránsitos y miradas. Armenia: Editorial Kínesis.
(2002). Fútbol y patria. El fútbol y las narrativas de la nación en la Argentina. Buenos Aires: Prometeo libros.

Bolívar, I.; Ferro, G.; Dávila, A. (2001). Cuadernos de nación: Nación y sociedad contemporánea, Bogotá: CINEP.

Centro Nacional de Consultoría. (2014).El poder del fútbol. Ministerio del interior. Bogotá.

Casa Editorial El Tiempo. (2000) Colombia Viva. Bogotá: Casa Editorial El Tiempo.

Gómez García, P. (1998). Las ilusiones de la "identidad".La etnia como pseudoconcepto. Gaceta de Antropología núm. 12.

Herrera, M. (2007).El memorial de las identidades: entre héroes y villanos. En la busca de sí y de los demás también, FoliosN.25.

Nietzsche, F. (s. f.). Sobre la utilidad y el prejuicio de la historia para la vida. Biblioteca nueva.

Ugas, G. (2007). La educada ignorancia: Un modo de ser del pensamiento. Caracas: TAPECS.

Vargas Llosa, M. citado en Galo Mora, W. (2003). Patria... ¿es la selección nacional de fútbol? Una lectura antropológica. Tesis de grado para obtener el título de Antropólogo en la Universidad Politécnica Salesiana, Quito. 
